\title{
Electricity Demand Projection Using a Path-Coefficient Analysis and BAG-SA Approach: A Case Study of China
}

\author{
Qunli Wu and Chenyang Peng \\ Department of Economics and Management, North China Electric Power University, Baoding 071003, China \\ Correspondence should be addressed to Chenyang Peng; ncepupengchenyang@163.com
}

Received 7 January 2017; Revised 18 March 2017; Accepted 27 March 2017; Published 9 April 2017

Academic Editor: Gabriella Bretti

Copyright (C) 2017 Qunli Wu and Chenyang Peng. This is an open access article distributed under the Creative Commons Attribution License, which permits unrestricted use, distribution, and reproduction in any medium, provided the original work is properly cited.

\begin{abstract}
Path-coefficient analysis is utilized to investigate the direct and indirect effects of economic growth, population growth, urbanization rate, industrialization level, and carbon intensity on electricity demand of China. To improve the projection accuracy of electricity demand, this study proposes a hybrid bat algorithm, Gaussian perturbations, and simulated annealing (BAG-SA) optimization method. The proposed BAG-SA algorithm not only inherits the simplicity and efficiency of the standard BA with a capability of searching for global optimality but also enhances local search ability and speeds up the global convergence rate. The BAG-SA algorithm is employed to optimize the coefficients of the multiple linear and quadratic forms of electricity demand estimation model. Results indicate that the proposed algorithm has higher precision and reliability than the coefficients optimized by other single-optimization methods, such as genetic algorithm, particle swarm optimization algorithm, or bat algorithm. And the quadratic form of BAG-SA electricity demand estimation model has better fitting ability compared with the multiple linear form of the model. Therefore, the quadratic form of the model is applied to estimate electricity demand of China from 2016 to 2030 . The findings of this study demonstrate that China’s electricity demand will reach 14925200 million KWh in 2030.
\end{abstract}

\section{Introduction}

Electrical energy is a pivotal input for the social and economic development of a country [1]. Thus, the analysis of energy issues and the development of energy policy options are of supreme importance [2]. In the process of the rapid economic growth, China's electricity consumption increased from 68304 million KWh in 1990 to 5863707 million KWh in 2015 , and the electricity consumption of China is expected to continue increasing in the coming years $[3,4]$. In order to ensure the stability of China's economic development and the formulation of relevant energy policies, the estimation of electricity demand is still an essential work. A better projection of electricity demand with good precision will be conductive for developing a scientific power supply strategy, financing planning, and electricity management [5].

There is a wealth of literature on the prediction of electricity demand. Mathematical models [1, 6-12], econometricbased models [13-18], and artificial intelligence methods [5, 19-22] have been used for electricity demand prediction.
Econometric-based models mainly include regression-based methods, times series methods, and state space and Kalman filtering models. However, a drawback of regression-based models is that they are highly dependent on the availability and reliability of external factors over the forecasting period [5]. Many efforts towards data collection and estimation should be made when carrying out regression modeling. Moreover, time series models cannot solve the problems such as multivariable and heteroscedasticity problems [5]. During the past few decades, artificial intelligence methods have gained some achievements in electricity demand, since they do not require any complex mathematical formulations or quantitative correlations between inputs and outputs [23]. Mathematical models are the most popular tools for forecasting the electricity demand. These models can be defined based on socioeconomic indicators, and the optimal coefficients are applied to specify the importance of each indicator [10]. In the past few years, the way to determine the optimal coefficients has been the focus of a large body of studies. 
TABLE 1: A brief review of previous studies.

\begin{tabular}{|c|c|c|c|c|c|}
\hline Source & Method & Model & Country & Period of time & Independent variables \\
\hline Ozturk et al. (2005) & $\begin{array}{l}\text { Genetic algorithm } \\
\text { (GA) }\end{array}$ & $\begin{array}{l}\text { Exponential } \\
\text { Quadratic }\end{array}$ & Turkey & $1980-2001$ & $\begin{array}{l}\text { Gross national } \\
\text { product (GDP) } \\
\text { Population } \\
\text { Import figure } \\
\text { Export figure }\end{array}$ \\
\hline Ünler (2008) & $\begin{array}{c}\text { Particle swarm } \\
\text { optimization (PSO) }\end{array}$ & $\begin{array}{c}\text { Linear } \\
\text { Quadratic }\end{array}$ & Turkey & 1979-2005 & $\begin{array}{c}\text { GDP } \\
\text { Population } \\
\text { Import figure } \\
\text { Export figure }\end{array}$ \\
\hline Toksari (2009) & $\begin{array}{c}\text { Ant colony } \\
\text { optimization (ACO) }\end{array}$ & $\begin{array}{c}\text { Linear } \\
\text { Quadratic }\end{array}$ & Turkey & 1979-2006 & $\begin{array}{c}\text { GDP } \\
\text { Population } \\
\text { Import figure } \\
\text { Export figure } \\
\end{array}$ \\
\hline Amjadi et al. (2010) & PSOGA & $\begin{array}{c}\text { Linear } \\
\text { Quadratic }\end{array}$ & Iran & 1980-2006 & $\begin{array}{c}\text { GDP } \\
\text { Population } \\
\text { Number of electricity } \\
\text { customers } \\
\text { Average price of } \\
\text { electricity } \\
\end{array}$ \\
\hline Kiran et al. (2012) & $\begin{array}{l}\text { Artificial bee colony } \\
\text { (ABC) } \\
\text { PSO }\end{array}$ & $\begin{array}{c}\text { Linear } \\
\text { Quadratic }\end{array}$ & Turkey & 1990-2009 & $\begin{array}{c}\text { GDP } \\
\text { Population } \\
\text { Import figure } \\
\text { Export figure } \\
\end{array}$ \\
\hline Yu et al. (2012) & $\begin{array}{c}\text { Hybridization of PSO } \\
\text { and GA }\end{array}$ & $\begin{array}{c}\text { Linear } \\
\text { Quadratic } \\
\text { Exponential }\end{array}$ & China & 1990-2009 & $\begin{array}{c}\text { GDP } \\
\text { Population } \\
\text { Economic structure } \\
\text { Urbanization rate }\end{array}$ \\
\hline Askarzadeh (2014) & $\begin{array}{l}\text { Different PSO } \\
\text { variants }\end{array}$ & $\begin{array}{l}\text { Exponential } \\
\text { Quadratic }\end{array}$ & Iran & 1982-2009 & $\begin{array}{c}\text { GDP } \\
\text { Population } \\
\text { Import figure } \\
\text { Export figure }\end{array}$ \\
\hline Toksari (2016) & $\begin{array}{l}\text { Hybridization of } \\
\text { ACO and iterated } \\
\text { local search (ILS) }\end{array}$ & $\begin{array}{c}\text { Linear } \\
\text { Quadratic }\end{array}$ & Turkey & $1990-2013$ & $\begin{array}{c}\text { GDP } \\
\text { Population } \\
\text { Import figure } \\
\text { Export figure }\end{array}$ \\
\hline
\end{tabular}

Given their stochastic characteristics and global search ability, metaheuristic optimization algorithms have been employed to estimate electricity demand precisely. The main advantage of these optimization algorithms is that there is higher chance to find optimal or near-optimal solution in complicated problems [10]. In the literature, genetic algorithm (GA), particle swarm optimization (PSO) algorithm, and other traditional single-optimization algorithms or hybridization of them has been proposed by various authors to estimate the coefficients of the estimation models. In this paper, Table 1 displays a brief description of these methods and their applications. However, the coefficients of these forecasting models determined by the traditional single-optimization approaches, for instance, GA and PSO algorithm, have some evident deficiencies [24, 25]. Therefore, in order to obtain better forecasting results, a new hybrid optimization algorithm should be established different from previous approaches.

In this paper, in the light of Gaussian perturbations and simulated annealing algorithm, an improved bat algorithm is proposed to determine the optimal coefficients of the two forms of electricity demand estimation model. The influence mechanism of the affecting factors of China's electricity demand is investigated by implementing a path-coefficient analysis. And the selected factors such as gross domestic product (GDP), population, urbanization rate, industrialization level, and carbon intensity are regarded as the inputs of the two forms of the model. The electricity demand estimation models in this study are multiple linear and quadratic forms. Observed data from 1990 to 2015 (26 years) are utilized to train and test the multiple linear and quadratic models. Then the electricity demand of China from 2016 to 2030 can be predicted.

The remainder of this paper is organized as follows. The factors affecting electricity demand and the path-coefficient analysis are discussed in Section 2. Then, Section 3 presents the proposed hybrid optimization algorithm. In Section 4, the BAG-SA electricity demand estimation model is developed, and future electricity demand of China is forecasted in Section 5. Finally, Section 6 offers some conclusions. 


\section{Selection of Factors Affecting Electricity Demand and Path-Coefficient Analysis}

2.1. Factors Affecting Electricity Demand in China. From the existing literature, it can be seen that electricity demand in China is mainly influenced by economic growth, population, urbanization rate, and industrialization level. In the lowcarbon economic development pattern, electricity demand should be also impacted by the carbon emission constraint.

(1) Economic Growth. The available supply of the electric industry has positive implications on the rapid and steady development of economy. Many studies corroborated that there is a long-run steady equilibrium between electricity demand and economic growth, and economic growth is the fundamental reason for the growth of electricity demand [2628]. Therefore, the effect of GDP on electricity demand is measured in this paper.

(2) Population. Population is an important factor to promote the growth of electricity demand. Electricity is the main type in household energy consumption. There is a strong positive linear relationship between population and electricity demand [29]. Also, Holtedahl and Joutz found that population can have a positive influence on electricity demand by establishing a residential electricity demand function [30]. China is the most populous country in the world, and the population reached 1.375 billion in 2015. Due to the large population base of China, total population can influence the change of electricity demand.

(3) Urbanization Rate. Lin [31] considered that the impact of urbanization rate on electricity demand is more significant compared to population growth. In the process of urbanization, the construction of the large-scale urban infrastructure, housing, and transportation system would spur the rapid development of building materials, metallurgy, and other high energy consuming industries, thus promoting the rapid growth of industrial, agricultural, and residential electricity demand. Therefore, urbanization rate (the share of urban population to total population) should be considered as an important electricity demand factor.

(4) Industrialization Level. Industrialization is a process of the rising proportion of industrial value added in the GDP. Some studies confirmed that the industrial sector is the main consumer of electrical energy, and the industrial sector is also an important reason to lead to the increment of electricity consumption unit GDP [32]. Hence, industrialization level (the proportion of industrial value added in the GDP) is selected as another factor affecting electricity demand in this paper.

(5) Carbon Emission Constraint. In order to fulfill the commitments of carbon emission reduction, Chinese government conceived carbon emission unit GDP (carbon intensity) as one of the core indicators to establish the low-carbon economic development system. The essences of low-carbon economy are the change of the way to use energy, the optimization of energy structure, and the improvement of energy efficiency. Therefore, the main measures to develop low-carbon economy are reducing coal consumption and increasing the proportion of coal used for power generation. Electricity as a clean and efficient energy will become the main energy type of the low-carbon energy system. In current study, carbon emission constraint (carbon intensity) is chosen as a factor influencing electricity demand of China.

2.2. Data Management. In this paper, GDP is measured in constant RMB of 1990 (billion Yuan). Electricity demand is measured in million KWh. The population is the total population (billion persons). Urbanization rate is the share of urban population to total population (\%). Industrialization level can be defined as the proportion of industrial value added in the GDP (\%). Carbon emission constraint is indicated by carbon intensity (tc/10 4 Yuan). Carbon emission data can be obtained from the energy consumption of each variety and its carbon emission coefficient. Besides, the carbon emission coefficients stem from the computing results of the Energy Research Institute of National Development and Reform Commission; that is, coal is $0.7476 \mathrm{tc} / \mathrm{tce}$ (tonnes of coal equivalent in caloric value calculation), oil is $0.5825 \mathrm{tc} / \mathrm{tce}$, and natural gas is $0.4435 \mathrm{tc} / \mathrm{tce}$. All annual data from 1990 to 2015 are collected from $[3,4]$.

2.3. Path-Coefficient Analysis. Path-coefficient analysis is conducted to further investigate the mechanism of the affecting factors of electricity demand. Path-coefficient analysis can provide an approach to distinguish direct and indirect effects and measure the relative importance of the causal factors [33]. Let $x_{1}, x_{2}, \ldots, x_{k}$ be the independent variables (the selected affecting factors), and let $y$ be the dependent variable (electricity demand). $r_{i j}$ can represent the simple correlation coefficients between $x_{i}$ and $x_{j}$, and $r_{i y}$ are the simple correlation coefficients between $x_{i}$ and $y$. Then, the decomposed equations (path-coefficient analysis model) of all simple coefficients are as follows:

$$
\begin{aligned}
& p_{1 y}+r_{12} p_{2 y}+\cdots+r_{1 k} p_{k y}=r_{1 y}, \\
& r_{21} p_{1 y}+p_{2 y}+\cdots+r_{2 k} p_{k y}=r_{2 y},
\end{aligned}
$$

$$
r_{k 1} p_{1 y}+r_{k 2} p_{2 y}+\cdots+p_{k y}=r_{k y}
$$

where $p_{i y}$ is the direct path, namely, the partial correlation coefficient of $x_{i}$ and $y$, representing the direct effect of $x_{i}$ on $y$. The direct determination coefficients of $x_{i}$ on $y$ are defined as $R_{i}^{2}=p_{i y}^{2} . r_{i j} p_{j y}$ is the indirect path, representing the indirect effect of $x_{i}$ on $y$ via $x_{j} . R_{i j}^{2}=2 p_{i y} r_{i j} p_{j y}$ represent the indirect determination coefficients of $x_{i}$ on $y$ via $x_{j} \cdot R_{(i)}^{2}=$ $R_{i}^{2}+\sum_{i \neq j} R_{i j}^{2}$ is the total effect which is the determination coefficient of $x_{i}$ on $y$. The basic meaning of (1) is that the simple correlation coefficient $r_{i j}$ can be decomposed into $p_{i y}$ (direct path) and $\sum_{i \neq j} r_{i j} p_{j y}$ (total indirect path). Because of the complexity of economic phenomena and the limitation 
TABLE 2: The direct and indirect contributions of different affecting factors to the electricity demand of China.

\begin{tabular}{|c|c|c|c|c|c|c|c|c|}
\hline $\begin{array}{l}\text { Independent } \\
\text { variable }\end{array}$ & Total effect & Direct effect & $\begin{array}{c}\text { Total indirect } \\
\text { effect }\end{array}$ & $\begin{array}{c}\text { Indirect effect } \\
\text { via } x_{1} \\
\end{array}$ & $\begin{array}{c}\text { Indirect effect } \\
\text { via } x_{2} \\
\end{array}$ & $\begin{array}{c}\text { Indirect effect } \\
\text { via } x_{3} \\
\end{array}$ & $\begin{array}{c}\text { Indirect effect } \\
\text { via } x_{4}\end{array}$ & $\begin{array}{c}\text { Indirect effect } \\
\text { via } x_{5}\end{array}$ \\
\hline$x_{1}$ & 0.946 & 0.329 & 0.617 & - & 0.169 & 0.317 & 0.062 & 0.069 \\
\hline$x_{2}$ & 0.935 & 0.173 & 0.762 & 0.321 & - & 0.307 & 0.063 & 0.071 \\
\hline$x_{3}$ & 0.942 & 0.320 & 0.622 & 0.326 & 0.166 & - & 0.062 & 0.068 \\
\hline$x_{4}$ & 0.579 & 0.142 & 0.437 & 0.338 & -0.168 & 0.337 & - & -0.070 \\
\hline$x_{5}$ & -0.929 & -0.072 & -0.857 & -0.318 & -0.170 & -0.305 & -0.064 & - \\
\hline
\end{tabular}

of people's understanding of economic phenomena, it is impossible to take into account all the factors that affect the dependent variable in models. Therefore, the path effect of the missing variables and the error terms on $y$ should be calculated, namely, the residual effect.

$$
p_{a y}=\sqrt{1-\sum_{i=1}^{k} p_{i y} r_{i y}}
$$

In present study, $y$ is the total electricity demand; $x_{i}(i=$ $1,2,3,4,5)$ are the independent variables, which are GDP $\left(x_{1}\right)$, total population $\left(x_{2}\right)$, the share of urban population to total population $\left(x_{3}\right)$, the proportion of industrial value added in the GDP $\left(x_{4}\right)$, and carbon intensity $\left(x_{5}\right)$. In the light of (1) and (2), the total determination coefficient is $R^{2}=$ 0.9985. Then, the residual effect is $p_{a y}=\sqrt{1-R^{2}}=0.039$, which indicates that the selected independent explanatory variables to the dependent variable (electricity demand) have reached $99.85 \%$, and the path-coefficient analysis grasps the main factors affecting electricity demand. The direct and indirect contributions of different affecting factors to electricity demand are listed in Table 2 apparently.

From Table 2, it can be seen that GDP, total population, and the share of urban population to total population are the main driving factors of the growth of electricity demand. Moreover, GDP and the share of urban population to total population have larger direct positive effects on electricity demand with the direct effects being 0.329 and 0.320 , respectively. Both the proportion of industrial value added in the GDP and carbon intensity have minor total effects on electricity demand. However, the realization of carbon emission reduction targets needs to change the mode of economic growth and promote the sustainable development pattern. Moreover, the targets need to push forward the transformation of primary industry to secondary industry or tertiary industry and accelerate the process of urbanization. Thus, the proportion of industrial value added in the GDP and carbon intensity can mainly have indirect effects on electricity demand through GDP and the share of urban population to total population.

\section{Hybrid BAG-SA Optimization Algorithm}

Bat algorithm (BA), which was put forward by Yang [34] in 2010, is a metaheuristic algorithm for global optimization based on echolocation behavior of bats. In terms of the accuracy and the effectiveness, BA can be superior to other existing algorithms, and the number of adjustable parameters is fewer. Hence, bat algorithm and its many variants have been widely used in various fields [35]. Although the basic BA has some advantages over other traditional optimization algorithms, the issues of slow convergence and low precision seem to still exist [36]. Like other nature-inspired algorithms, the efficiency and performance of BA rely on the balance between exploration and exploitation. To enhance the local search capability of BA, Cai et al. employed the Gaussian walk in the local turbulence rather than the initial uniform walk [37]. Compared with BA, simulated annealing (SA) has strong local search ability, which has been diffusely used in combinatorial optimization problems [38]. SA can obtain the minimum value of a function by simulating the state changes of particles from high temperature to low temperature. The transition probability of SA can be controlled by adjusting the temperature, which can effectively allow the system to jump out of any local optimum. Therefore, in order to optimize the coefficients of electricity demand estimation model more effectively, this paper attempts to employ the SA algorithm to enhance the bat algorithm, and the Gaussian perturbations in the mutation operation are adopted to further improve the local search property of BA. Through the numerical experiments for 20 test benchmarks, the simulation results show that the proposed BAG-SA method can enhance the global convergence, convergence speed, and precision of the basic BA apparently [39]. The details about the standard BA and SA approaches can be seen in [34] and [40], respectively.

In this study, the basic procedure of BAG-SA can be described: generate an initial population, and replace the best solutions with the new alternatives obtained by using SA algorithm, in accordance with the updating equations of the standard BA. Then, the locations can be perturbed by using the Gaussian perturbations to generate a set of new solutions. The specific steps of the BAG-SA can be summarized as follows.

Step 1. Initialize the positions, velocities, frequencies, pulse rates, and loudness of the population randomly.

Step 2. Assess the fitness value of each bat; then store the current position and fitness value, and retain the optimal solution in pbest.

Step 3. Determine the initial temperature. 
Step 4. Compute the adaption value of each bat in the current temperature according to the following formula:

$$
T F\left(x_{i}\right)=\frac{e^{\left(f(\text { pbest })-f\left(x_{i}\right)\right) / t}}{\sum_{i=1}^{N} e^{\left(f(p b e s t)-f\left(x_{i}\right)\right) / t}}
$$

Step 5. On the basis of the roulette strategy, an alternative pbest' can be obtained, and the velocity and position can be updated as follows:

$$
\begin{aligned}
& v_{i}^{t}=v_{i}^{t-1}+\left(x_{i}^{t}-\text { pbest }^{\prime}\right) f_{i}, \\
& x_{i}^{t}=x_{i}^{t-1}+v_{i}^{t} .
\end{aligned}
$$

Step 6. Compute the new fitness value of each bat and update the better positions. Then, find the optimal position pbest and its corresponding value using the Gaussian perturbations in the mutation operations. The new position can be generated by the following equation:

$$
x^{t+1}=x^{t}+\alpha \mu
$$

where $\mu$ is a random number sampled with the standard Gaussian distribution; $\alpha$ is a small value which is applied to adjust the search range of the walk for improving the local search capability.

Step 7. Carry out the cooling operation.

Step 8. If the termination condition can be satisfied, then output the results; otherwise, return to Step 4.

The aforementioned steps can be distinctly displayed in Figure 1.

\section{BAG-SA Electricity Demand Estimation Model for China}

4.1. Two-Form Estimation Model and Coefficient Optimization for the Current Data. Based on the selected affecting factors, the multiple linear and quadratic forms of electricity demand estimation model can be established. These two forms are described as follows:

BAG-SA multiple linear form (BGS-ML):

$$
E_{\mathrm{ML}}=w_{0}+\sum_{i=1}^{n} w_{i} X_{i}
$$

BAG-SA quadratic form (BGS-QUA):

$$
E_{\mathrm{QUA}}=w_{0}+\sum_{i=1}^{n} w_{i} X_{i}+\sum_{i=1}^{n} \sum_{j=i+1}^{n} m_{i j} X_{i} X_{j}+\sum_{i=1}^{n} t_{i} X_{i}^{2},
$$

$E$ is the electricity demand; $X_{i}$ and $X_{j}$ are the $i$ th and the $j$ th factors influencing electricity demand, respectively; $w_{0}, w_{i}, m_{i j}$, and $t_{i}$ are the coefficients of the above equations; and $n$ is the number of factors affecting electricity demand.

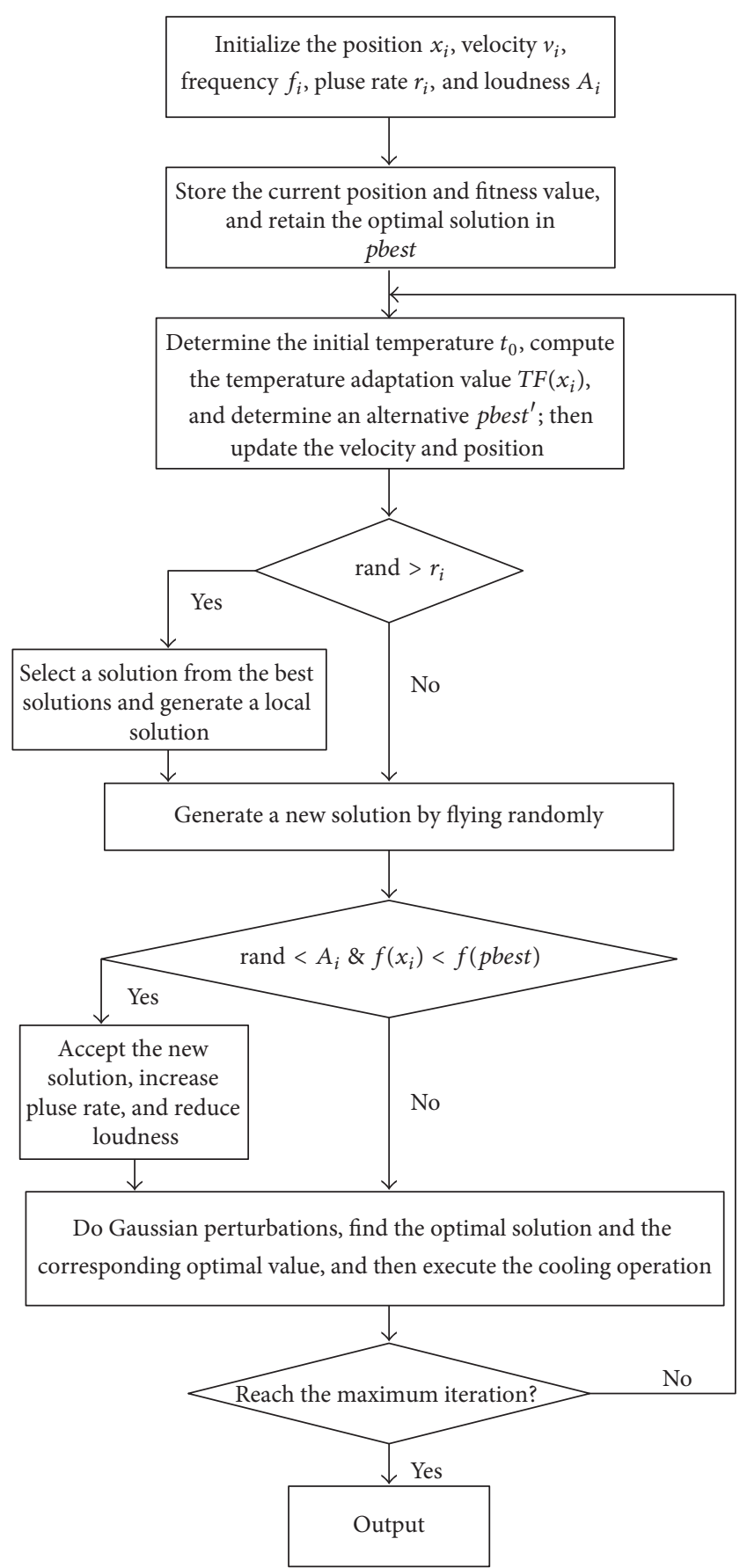

FIGURE 1: Flowchart of the proposed BAG-SA approach.

To obtain the optimal coefficients of the electricity demand estimation models, the proposed BAG-SA optimization approach is utilized to optimize the following function of model:

$$
\min f(s)=\frac{1}{T} \sum_{k=1}^{T}\left(Y_{k}-\widehat{Y_{k}}\right)^{2},
$$

where $T$ is the number of training sets; $Y_{k}$ is the $k$ th actual value of electricity consumption; $\widehat{Y}_{k}$ is the $k$ th prediction value of electricity consumption; $s$ represents the coefficients 
of (6) and (7) when the objective function meets the termination conditions of the algorithm.

Since this paper selects five variables as the inputs of the two forms of the electricity demand estimation model, 6 and 21 coefficients of the two forms need to be determined, respectively. The main parameters of the BAG-SA electricity demand estimation model are listed in Table 3.
4.2. Estimation Results. To estimate the coefficients of multiple linear form and quadratic form effectively, the BAG-SA utilizes the observation data from 1990 to 2012 as the training set. When the BAG-SA algorithm reaches the max. iteration number, the optimal coefficients for the two electricity demand estimation models can be obtained:

$$
\begin{aligned}
& W_{\mathrm{ML}}=\left[w_{1}, w_{2}, w_{3}, \ldots, w_{6}\right]=[40.3757,0.3050,1.0306,-1.3843,1.1573,-0.68133] \\
& W_{\mathrm{QUA}}=\left[w_{0}, w_{1}, w_{2}, \ldots, w_{21}\right]=[-300.0640,0.3049,0.9896,-0.9843,4.7073 \\
& \quad-1.9913,0.0000,0.0000,0.0000,0.0000,0.0090,0.0082,0.0625,0.0072,0.0898,0.0393,0.0000,0.0249,0.0151,0.0263 \\
& \quad-0.0014]
\end{aligned}
$$

The observations in 2013-2015 are selected as the testing set to corroborate the proposed models. The actual and the prediction data from 2009 to 2015 are shown in Figure 2. From Figure 2, it can be seen that the obtained models display favorable fitting ability. In this paper, using the training data (1990-2012) and the testing data (2013-2015), GA, PSO, $\mathrm{BA}$, and BAG-SA are compared for multiple linear and quadratic forms. MAPE and $R^{2}$ in the training and testing sets are described in Table 4 . The experimental results show that the hybrid BAG-SA optimization algorithm has higher forecasting accuracy than other optimization methods (GA, PSO, and BA). In the light of MAPE and $R^{2}$, the BAGSA electricity demand estimation models display powerful forecasting capability.

Moreover, from Figure 2 and Table 4, it can be concluded that the quadratic form of BAG-SA (BGS-QUA) has better fitting ability than the multiple linear form of BAG-SA (BGS$\mathrm{ML})$. Therefore, only the BGS-QUA is applied to accomplish the estimation of China's electricity demand from 2016 to 2030 .

\section{Future Estimation}

In order to estimate future electricity demand of China and reflect the impact of carbon emission reduction policies on future electricity demand, the major assumptions of the selected affecting factors are set as follows.

(1) Economic Growth. According to the estimation results of China's average annual GDP growth rate from International Energy Agency (2010), Citibank (2011), World Bank (2012), and Hong Kong and Shanghai Banking Corporation (2012) in 2016-2030, the average forecasting values of the agencies are regarded as the China's economic growth rate of 2016-2020 and 2020-2030, respectively [41].

(2) Population Growth. The average annual growth rate of China's population was approximately $0.5 \%$ in 2006-2015. The Fifth Plenary Session of the 18th Central Committee of the Communist Party of China proposed that each family can raise two children in October 2015. According to the fertility willingness survey of the National Health and Family
Planning Commission of China, it can be seen that about 15 million-20 million couples conform with the new policy, and only the couples of $50 \%-60 \%$ have the fertility willingness with the increment of newborns reaching 7.5 million-12 million in the short term. If the fertility can be achieved within 5 years, the annual increase of newborns will be 1.5 million-2.4 million. Then, the birth rate will increase to $1.3 \%-1.4 \%$, and the annual mortality rate is around $0.7 \%$. China's future population growth rate will be around $0.6 \%-0.7 \%$. Hence, in this study, the average annual growth rate of population is supposed to be $0.65 \%$ in $2016-2030$.

(3) Urbanization Rate. Regarding the large difference of income level and the amount of electricity consumption between China's rural and urban areas, there is an assumption about the future trend of urbanization. In the "New National Urbanization Planning," China's State Council announced that the goal of about $60 \%$ urbanization rate should be achieved by 2020. According to "Report of State Council on the Work of the Construction of Urbanization," by 2030, the urbanization rate will reach about $70 \%$. In 2015, the urbanization rate was $56.1 \%$. Therefore, the average annual growth rate of urbanization rate should be $1.3 \%$ in 2016-2020, and the average annual growth rate will be $1.6 \%$ in 2020-2030.

(4) Industrialization Level. On the basis of the research "Industrial Development Policy in Developing Countries," which is jointly hosted by the United Nations Industrial Development Organization and the World Bank, China can be in the stage of industrialization. During the period of the 12th Five-Year Plan of China, the average annual growth rate of the proportion of industrial value added in the GDP was $-3.3 \%$. The adjustment and optimization of industrial structure can still be the goals of the 13th Five-Year Plan of China, and the industrialization is gradually transformed from scale expansion to quality improvement under the strict restriction of energy saving and emission reduction targets. Thus, the average annual growth rate of the proportion of industrial value added in the GDP should be $-3.3 \%$ in 2016-2020, and the average annual growth rate will be $-3.0 \%$ in 2020-2030. 


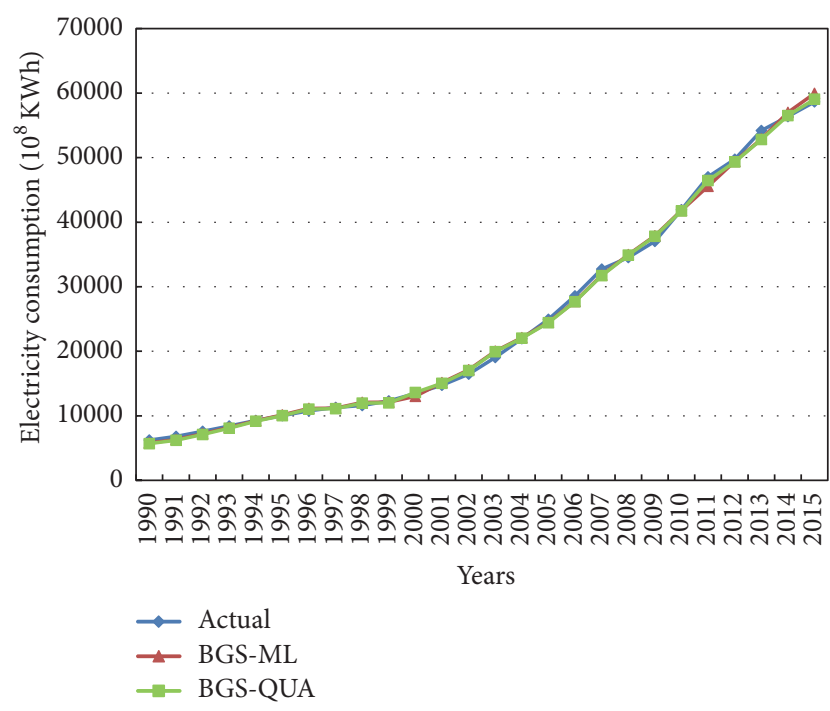

Figure 2: Comparison of actual and prediction values of electricity consumption (1990-2015).

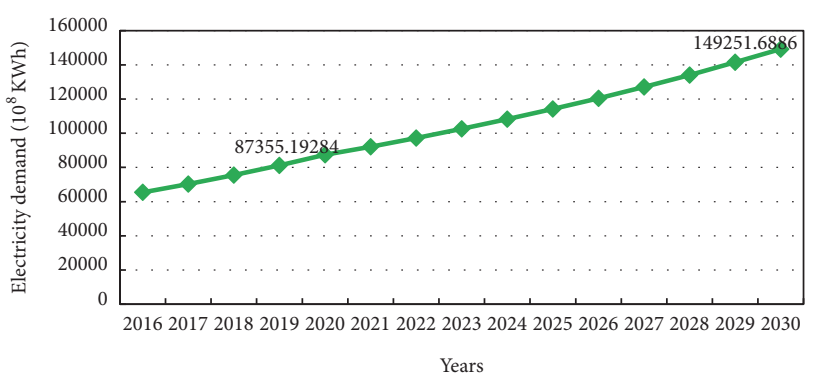

FIGURE 3: Electricity demand of China from 2016 to 2030.

(5) Carbon Intensity. In China, the strong implementation of energy-saving emission reduction policies can directly affect the growth of electricity demand, and the goal of energy conservation and emission reduction seems to be more explicit. According to the low-carbon economic development goal of the "China's Sustainable Development Strategy Report" in 2009, Chinese government promised that carbon intensity (carbon emission unit GDP) in 2020 should be decreased by $50 \%$ compared to that of 2005 . Moreover, in the "Strengthen the Response to Climate Change ActionChina's National Autonomous Contributions" submitted by Chinese government to the United Nations, in 2030, the carbon emissions unit GDP will achieve the reduction of $60 \% \sim 65 \%$ compared to that of 2005 . This paper assumes that the carbon emissions unit GDP in 2020 and 2030 will be decreased by $50 \%$ and $65 \%$, respectively, compared with that in 2005. Therefore, the average annual growth rate of carbon intensity should be $-3.3 \%$ in $2016-2020$ and will be $-3.0 \%$ in $2020-2030$. Various variables settings are described in Table 5.

In the light of the future changes of different affecting factors from Table 5 , the estimation results of electricity demand are shown in Figure 3. By 2020, electricity demand will be
TABLE 3: Main parameters of the BAG-SA electricity demand estimation model.

\begin{tabular}{lc}
\hline Parameters & Values \\
\hline Initial population size & 30 \\
Initial loudness & 0.25 \\
Pulse rate & 0.5 \\
Minimum frequency & 0 \\
Maximum frequency & 2 \\
Max. iteration number & 200 \\
Initial temperature & 200 \\
Annealing constant & 0.6 \\
\hline
\end{tabular}

8735500 million KWh when achieving the carbon emission reduction target of 2020. And the electricity demand will reach 14925200 million KWh with realizing the carbon emission mitigation goal of 2030 .

\section{Conclusions}

The main conclusions that can be drawn from the present study are summarized as follows:

(1) Under the target of low-carbon economy, the influence mechanism of electricity demand of China is explored by implementing the path-coefficient analysis. The total determination coefficient indicates that the selected five explanatory variables to electricity demand have reached $99.85 \%$, and the path-coefficient analysis can capture the main factors affecting electricity demand.

(2) The proposed BAG-SA algorithm outperforms the coefficients optimized by single-optimization methods, such as GA, PSO, or BA, in terms of accuracy and reliability.

(3) According to MAPE and $R^{2}$, the quadratic form of BAG-SA electricity demand estimation model can find better solution than the multiple linear form of model, since the quadratic form can reflect better the variations of the selected indicators.

(4) With respect to future changes of affecting factors, the electricity demand of China from 2016 to 2030 can be predicted by using the quadratic form based on the BAG-SA approach. Experimental results show that China's electricity demand will be 14925200 million KWh in 2030.

\section{Conflicts of Interest}

The authors declare that there are no conflicts of interest.

\section{Authors' Contributions}

Qunli Wu designed this paper and provided overall guidance; Chenyang Peng wrote the whole manuscript. 
TABLE 4: Comparison of results from various electricity demand estimation models.

\begin{tabular}{|c|c|c|c|c|}
\hline Models & Optimization algorithms & $R^{2}$ & MAPE of training set & MAPE of testing set \\
\hline \multirow{4}{*}{ Multiple linear } & GA & 0.9871 & $7.0871 \%$ & $2.9348 \%$ \\
\hline & PSO & 0.9908 & $6.3245 \%$ & $2.5802 \%$ \\
\hline & BA & 0.9929 & $5.9254 \%$ & $2.3702 \%$ \\
\hline & BAG-SA & 0.9943 & $5.1729 \%$ & $1.9288 \%$ \\
\hline \multirow{4}{*}{ Quadratic } & GA & 0.9883 & $6.6950 \%$ & $2.7215 \%$ \\
\hline & PSO & 0.9915 & $6.1841 \%$ & $2.5241 \%$ \\
\hline & BA & 0.9940 & $5.6614 \%$ & $2.2646 \%$ \\
\hline & BAG-SA & 0.9985 & $2.7883 \%$ & $1.1772 \%$ \\
\hline
\end{tabular}

TABLE 5: Various factors settings.

\begin{tabular}{|c|c|c|c|c|c|}
\hline Year & $\begin{array}{l}\text { GDP growth rate per } \\
\text { year }(\%)\end{array}$ & $\begin{array}{l}\text { Population growth } \\
\text { rate per year }(\%)\end{array}$ & $\begin{array}{l}\text { Urbanization growth } \\
\text { rate per year }(\%)\end{array}$ & $\begin{array}{l}\text { Proportion of } \\
\text { industrial value added } \\
\text { in the GDP growth } \\
\text { rate per year }(\%)\end{array}$ & $\begin{array}{c}\text { Carbon intensity } \\
\text { growth rate per year } \\
(\%)\end{array}$ \\
\hline 2016-2020 & 7.5 & 0.65 & 1.3 & -3.3 & -3.3 \\
\hline 2020-2030 & 5.5 & 0.65 & 1.6 & -3.0 & -3.0 \\
\hline
\end{tabular}

\section{Acknowledgments}

This study is supported by the Humanities and Social Sciences Planning Foundation of the Ministry of Education of China (Grant no. 16YJA790052).

\section{References}

[1] M. D. Toksar1, "Estimating the net electricity energy generation and demand using the ant colony optimization approach: case of Turkey," Energy Policy, vol. 37, no. 3, pp. 1181-1187, 2009.

[2] Z. Utlu and A. Hepbasli, "Assessment of the energy utilization efficiency in the Turkish transportation sector between 2000 and 2020 using energy and exergy analysis method," Energy Policy, vol. 34, no. 13, pp. 1611-1618, 2006.

[3] NBSC, China Statistics Yearbook 2015, China Statistics Press, Beijing, China, 2015.

[4] NBSC, Annual Report on the National Economy and Social Development of P.R. China 2015, Chinese Statistics Press, Beijing, China, 2016.

[5] S. Yu, K. Wang, and Y.-M. Wei, "A hybrid self-adaptive Particle Swarm Optimization-Genetic Algorithm-Radial Basis Function model for annual electricity demand prediction," Energy Conversion and Management, vol. 91, pp. 176-185, 2015.

[6] H. K. Ozturk, H. Ceylan, O. E. Canyurt, and A. Hepbasli, "Electricity estimation using genetic algorithm approach: a case study of Turkey," Energy, vol. 30, no. 7, pp. 1003-1012, 2005.

[7] M. H. Amjadi, H. Nezamabadi-Pour, and M. M. Farsangi, "Estimation of electricity demand of Iran using two heuristic algorithms," Energy Conversion and Management, vol. 51, no. 3, pp. 493-497, 2010.

[8] M. S. Kıran, E. Özceylan, M. Gündüz, and T. Paksoy, "Swarm intelligence approaches to estimate electricity energy demand in Turkey," Knowledge-Based Systems, vol. 36, pp. 93-103, 2012.
[9] M. D. Toksari, "A hybrid algorithm of Ant Colony Optimization (ACO) and Iterated Local Search (ILS) for estimating electricity domestic consumption: case of Turkey," International Journal of Electrical Power and Energy Systems, vol. 78, pp. 776-782, 2016.

[10] A. Askarzadeh, "Comparison of particle swarm optimization and other metaheuristics on electricity demand estimation: a case study of Iran," Energy, vol. 72, pp. 484-491, 2014.

[11] A. Ünler, "Improvement of energy demand forecasts using swarm intelligence: the case of Turkey with projections to 2025," Energy Policy, vol. 36, no. 6, pp. 1937-1944, 2008.

[12] S. Yu, Y.-M. Wei, and K. Wang, "A PSO-GA optimal model to estimate primary energy demand of China," Energy Policy, vol. 42, pp. 329-340, 2012.

[13] V. Bianco, O. Manca, and S. Nardini, "Electricity consumption forecasting in Italy using linear regression models," Energy, vol. 34, no. 9, pp. 1413-1421, 2009.

[14] S. S. Pappas, L. Ekonomou, D. C. Karamousantas, G. E. Chatzarakis, S. K. Katsikas, and P. Liatsis, "Electricity demand loads modeling using AutoRegressive Moving Average (ARMA) models," Energy, vol. 33, no. 9, pp. 1353-1360, 2008.

[15] Y. Wang, J. Wang, G. Zhao, and Y. Dong, "Application of residual modification approach in seasonal ARIMA for electricity demand forecasting: a case study of China," Energy Policy, vol. 48, pp. 284-294, 2012.

[16] Z. Dilaver Zafer and L. C. Hunt, "Industrial electricity demand for Turkey: a structural time series analysis," Energy Economics, vol. 33, no. 3, pp. 426-436, 2011.

[17] I. Arisoy and I. Ozturk, "Estimating industrial and residential electricity demand in Turkey: a time varying parameter approach," Energy, vol. 66, pp. 959-964, 2014.

[18] R. Inglesi-Lotz, "The evolution of price elasticity of electricity demand in South Africa: a Kalman filter application," Energy Policy, vol. 39, no. 6, pp. 3690-3696, 2011. 
[19] G. Zahedi, S. Azizi, A. Bahadori, A. Elkamel, and S. R. Wan Alwi, "Electricity demand estimation using an adaptive neuro-fuzzy network: a case study from the Ontario province-Canada," Energy, vol. 49, no. 1, pp. 323-328, 2013.

[20] A. Azadeh, M. Saberi, A. Gitiforouz, and Z. Saberi, "A hybrid simulation-adaptive network based fuzzy inference system for improvement of electricity consumption estimation," Expert Systems with Applications, vol. 36, no. 8, pp. 11108-11117, 2009.

[21] K. Kandananond, "Forecasting electricity demand in Thailand with an artificial neural network approach," Energies, vol. 4, no. 8, pp. 1246-1257, 2011.

[22] M. A. Behrang, E. Assareh, M. R. Assari, and A. Ghanbarzadeh, "Assessment of electricity demand in Iran's industrial sector using different intelligent optimization techniques," Applied Artificial Intelligence, vol. 25, no. 4, pp. 292-304, 2011.

[23] S. Yu, K. Zhu, and F. Diao, "A dynamic all parameters adaptive BP neural networks model and its application on oil reservoir prediction," Applied Mathematics and Computation, vol. 195, no. 1, pp. 66-75, 2008.

[24] K. Wang, A. Salhi, and E. S. Fraga, "Process design optimisation using embedded hybrid visualisation and data analysis techniques within a genetic algorithm optimisation framework," Chemical Engineering and Processing: Process Intensification, vol. 43, no. 5, pp. 657-669, 2004.

[25] F. van den Bergh and A. P. Engelbrecht, "A cooperative approach to particle swarm optimization," IEEE Transactions on Evolutionary Computation, vol. 8, no. 3, pp. 225-239, 2004.

[26] D. I. Stern, "Energy and economic growth in the USA: a multivariate approach," Energy Economics, vol. 15, no. 2, pp. 137150, 1993.

[27] G. Hondroyiannis, S. Lolos, and E. Papapetrou, "Energy consumption and economic growth: assessing the evidence from Greece," Energy Economics, vol. 24, no. 4, pp. 319-336, 2002.

[28] U. Soytas and R. Sari, "Energy consumption and GDP: causality relationship in G-7 countries and emerging markets," Energy Economics, vol. 25, no. 1, pp. 33-37, 2003.

[29] F. Egelioglu, A. A. Mohamad, and H. Guven, "Economic variables and electricity consumption in Northern Cyprus," Energy, vol. 26, no. 4, pp. 355-362, 2001.

[30] P. Holtedahl and F. L. Joutz, "Residential electricity demand in Taiwan," Energy Economics, vol. 26, no. 2, pp. 201-224, 2004.

[31] B. Lin, "Structural changes, efficiency improvement and electricity demand forecasting," Economic Research Journal, no. 5, pp. 57-65, 2003.

[32] X. He, X. Liu, and Y. Lin, "China's electricity demand forecast under urbanization process," Economic Research Journal, vol. 1, pp. 118-130, 2009.

[33] S. Wright, "The method of path coefficients," The Annals of Mathematical Statistics, vol. 5, no. 3, pp. 161-215, 1934.

[34] X.-S. Yang, "A new metaheuristic bat-inspired algorithm," in Nature Inspired Cooperative Strategies for Optimization (NICSO 2010), pp. 65-74, Springer, 2010.

[35] X.-S. Yang and X. He, "Bat algorithm: literature review and applications," International Journal of Bio-Inspired Computation, vol. 5, no. 3, pp. 141-149, 2013.

[36] L. dos Santos Coelho and A. Askarzadeh, "An enhanced bat algorithm approach for reducing electrical power consumption of air conditioning systems based on differential operator," Applied Thermal Engineering, vol. 99, pp. 834-840, 2016.

[37] X. Cai, L. Wang, Q. Kang, and Q. Wu, "Bat algorithm with gaussian walk," International Journal of Bio-Inspired Computation, vol. 6, no. 3, pp. 166-174, 2014.
[38] J. Behnamian and S. M. T. Fatemi Ghomi, "Development of a PSO-SA hybrid metaheuristic for a new comprehensive regression model to time-series forecasting," Expert Systems with Applications, vol. 37, no. 2, pp. 974-984, 2010.

[39] X.-S. He, W.-J. Ding, and X.-S. Yang, "Bat algorithm based on simulated annealing and gaussian perturbations," Neural Computing and Applications, vol. 25, no. 2, pp. 459-468, 2014.

[40] S. Kirkpatrick, C. D. Gelatt Jr., and M. P. Vecchi, "Optimization by simulated annealing," Science, vol. 220, no. 4598, pp. 671-680, 1983.

[41] Z. Han and Z. Li, "Analysis of economic comparison between China and the United States," The Journal of Quantitative \& Technical Economics, vol. 31, pp. 115-133, 2014. 


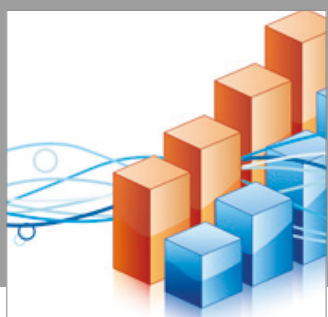

Advances in

Operations Research

vatersals

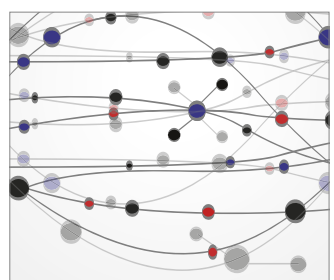

\section{The Scientific} World Journal
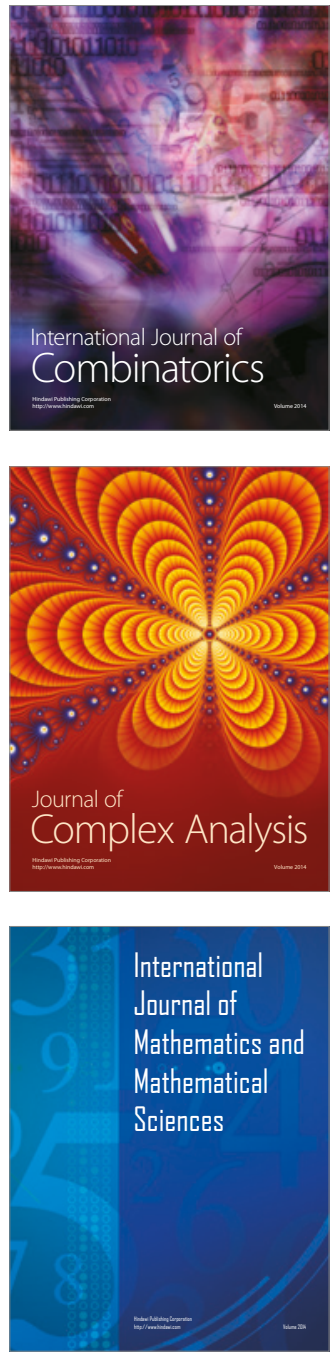
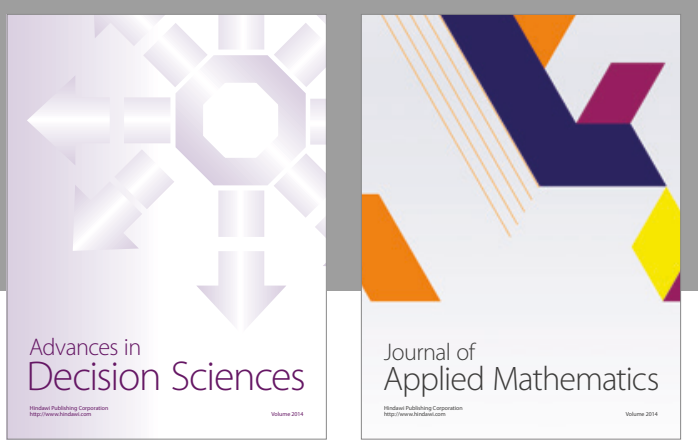

Algebra

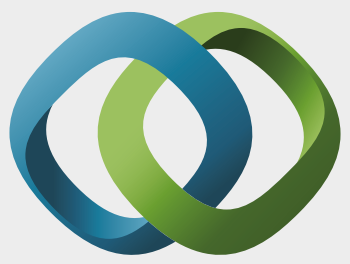

\section{Hindawi}

Submit your manuscripts at

https://www.hindawi.com
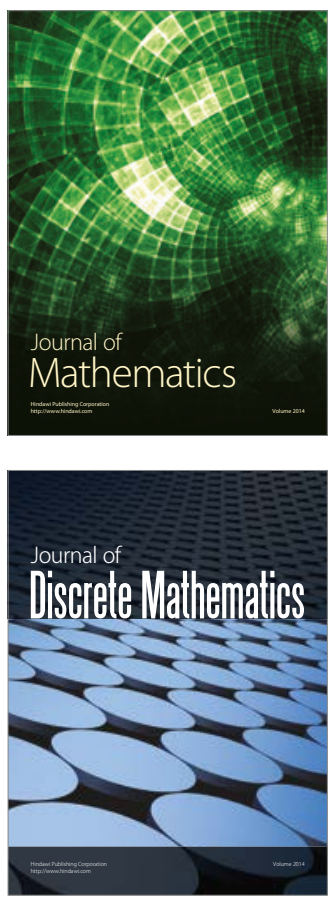

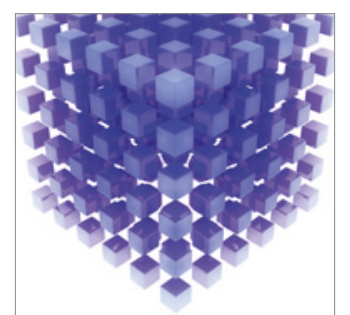

Mathematical Problems in Engineering
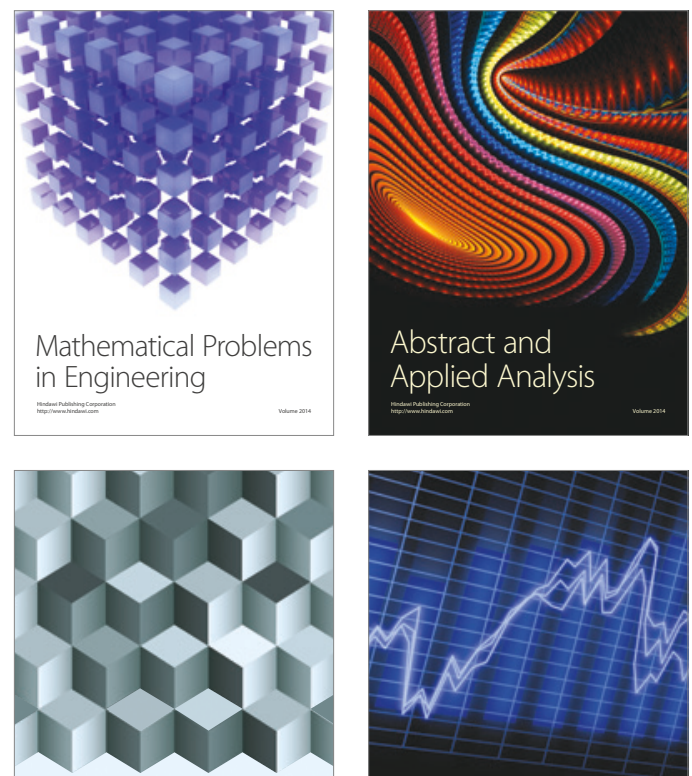

Journal of

Function Spaces

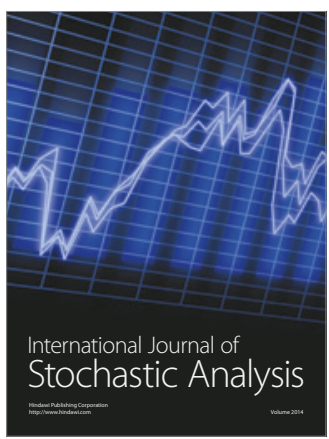

Probability and Statistics
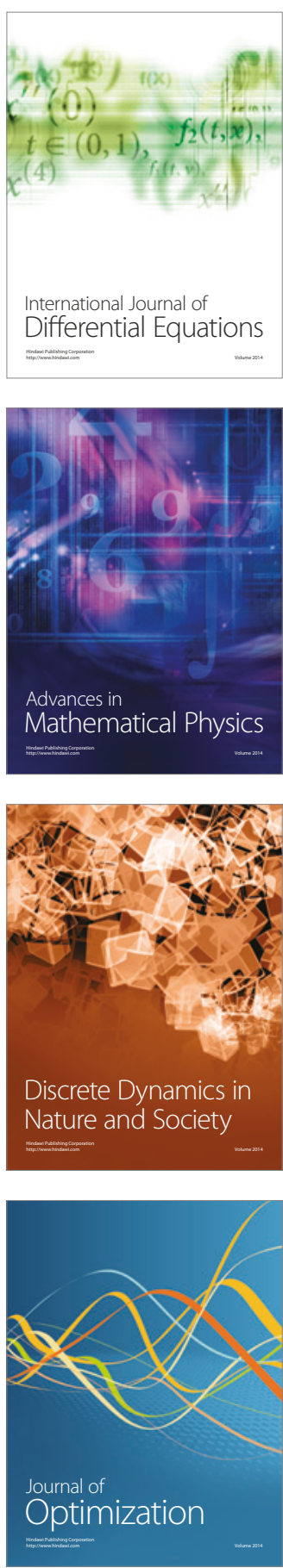